\title{
Maps hiding in plain sight
}

\author{
Bruce Jones *, Anthony Cavell, Michael Clarke, Robert Pratt \\ Taiwan National Universitye-mail: txrobotics@mac.com ; PLS, CFedS; Southern Methodist University; Yale \\ * Corresponding author
}

\begin{abstract}
Early Chinese elites were defined by their aristocratic control of land. That control came directly from the emperor and was documented on bronze ritual vessels, which were handed down from generation to generation. The land grant boundaries were defined using decorative symbols inscribed on bronze, and Western Zhou vessels containing these symbols were used to resolve land disputes. Methodical analysis comparing the inscriptions and symbols, combined with an understanding of early Chinese cartography and etymology, allows the bronze vessel land grants to be decoded.
\end{abstract}

Keywords: bronze ritual vessels, symbols, decode, land grant, Western Zhou

\section{China's Rosetta stone}

It was a standard land deal gone bad. Ge Bo made a deal with Mr. Peng. In exchange for a few fine horses and chariots, Ge Bo would transfer the taxed produce of thirty small farms to Mr. Peng. Mr. Peng delivered the horses and chariots. Ge Bo accepted the horses and chariots. However, Ge Bo failed to transfer the taxed produce from the farms.

Mr. Peng persuaded some friends in the government to settle the dispute. They decided against Ge Bo and went into the fields to perform what was called a livery of seisins to legally transfer the land from Ge Bo to Mr. Peng.

Apparently, Mr. Peng, for good reason, did not trust Ge Bo and had the affair permanently documented in bronze. The transaction was spelled out in detail in an inscription inside the bronze vessel (Feng, 2003).

The inscription (Figure 1) starts with the legal formalities: the date and location of the event. Next, it tells the background story of Mr. Peng having given Ge Bo horses and chariots in exchange for the taxed produce from the farms.

"The Elder of $\mathrm{Ge}$ [Ge Bo] violated this. Yiren and Qi [government officials] accompanied the Elder of $\mathrm{Ge}$ in tracing the field lines along pear grove in the valley of $\mathrm{Du}$ and the mulberry grove in the valley of [unreadable], crossing to the East Gate" (Eno, 2012). The officials then shovelled the dirt to make a surveyor's boundary mound (Eno, 2012, 38).

To make the transaction completely clear, Mr. Peng included a map on the bronze (Figure 2). Apparently, however, he did not tell anybody that he had done so.

The map was not a grid map like those we would be familiar with today. However, it included the necessary elements that would allow future surveyors, if they were familiar with the local landscape, to clearly recognize what lands were involved.

According to Chinese tradition, the bronze would be handed down and explained so that each new generation would know the origins and boundaries of their hereditary lands-just in case Ge Bo's family tried to contest the boundary later on.

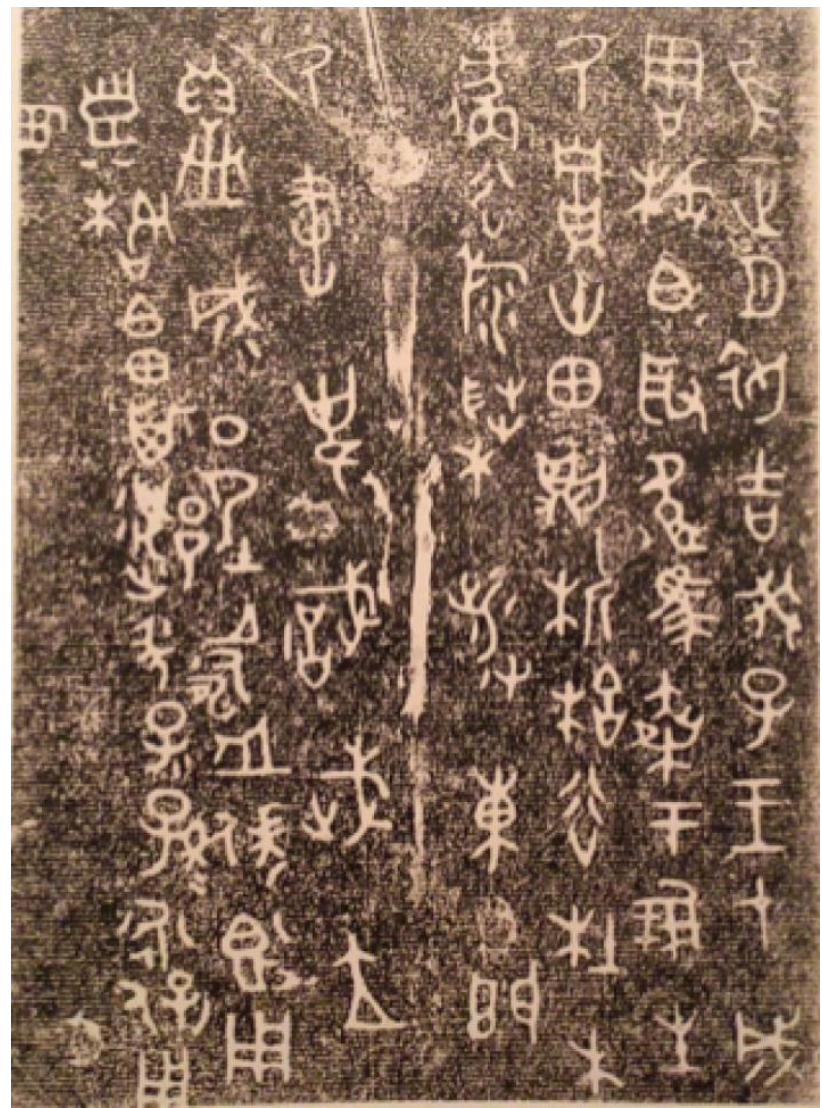

Figure 1. Rubbing of the inscription from Peng Sheng gui (Bronze Ritual Vessels and Musical Instruments from the Complete Collection of Treasures of the Palace Museum).

\section{Decoding the Peng Sheng gui}

The bronze that Mr. Peng had made was not large or particularly imposing. However, the interior inscription is why this bronze is famous in academic circles. We are unaware of any researcher who has correlated the interior inscription with any of the symbols on the outside of the bronze. 
It is standard procedure to look for repetition when decoding such inscriptions. In this case, the Peng Sheng gui inscription describes two different agricultural areas.

Visually, the Peng Sheng gui is dominated by two sections with rows of parallel lines (Figure 3 ). These rows mimic those seen in agriculture (Figure 4).

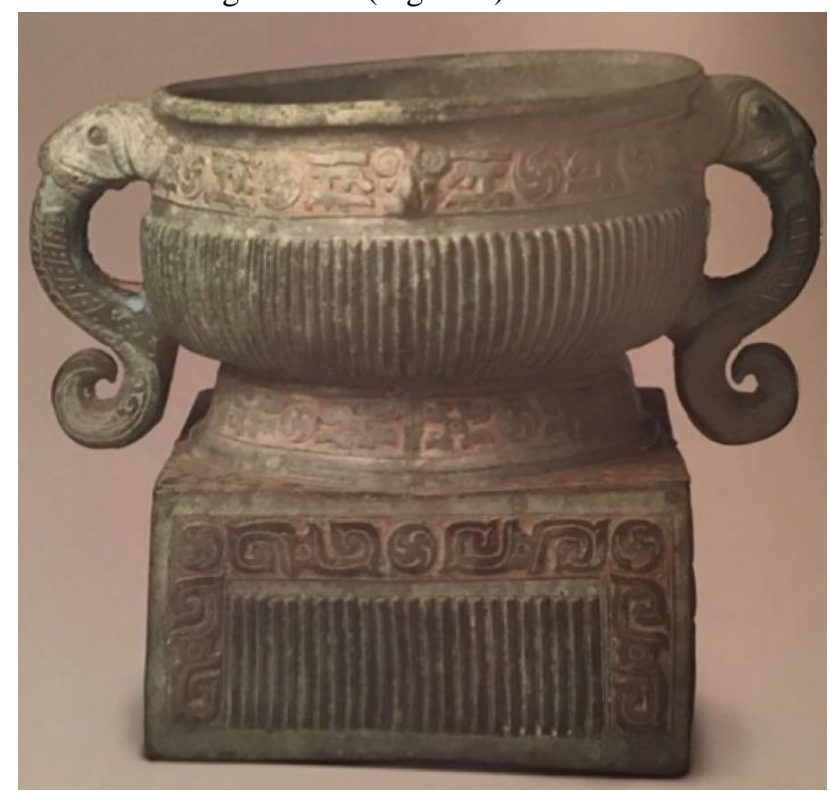

Figure 2. Peng Sheng gui.

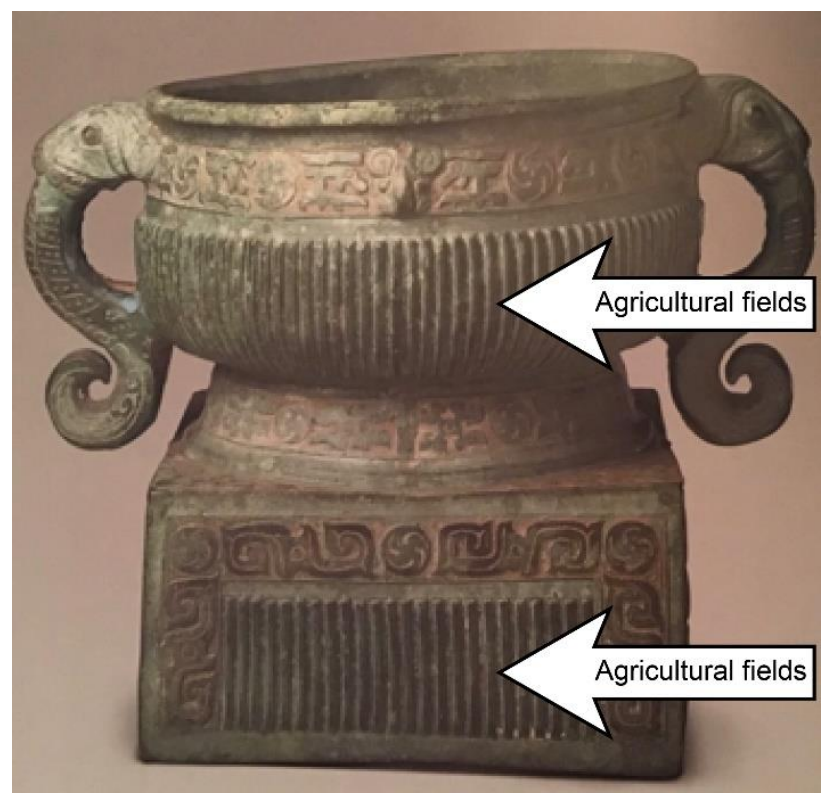

Figure 3. (left) shows Peng Shen gui symbols resembling agricultural fields.

It can therefore be concluded that the parallel rows of lines symbolize ploughed fields.

The inscription mentions two different valleys/streams, the Du Valley/stream and another valley/stream whose name is unreadable (henceforth referred to as the "X" stream).

On the Peng Sheng gui, we find the symbol for "stream" (Figure 5) bordering each section of the bronze (Figure 6) and separating the symbols denoting agricultural fields (Wilkinson, 2018, 230). We can conclude that the "stream" symbols are boundary markers for the farms as delineated by the surveyors.

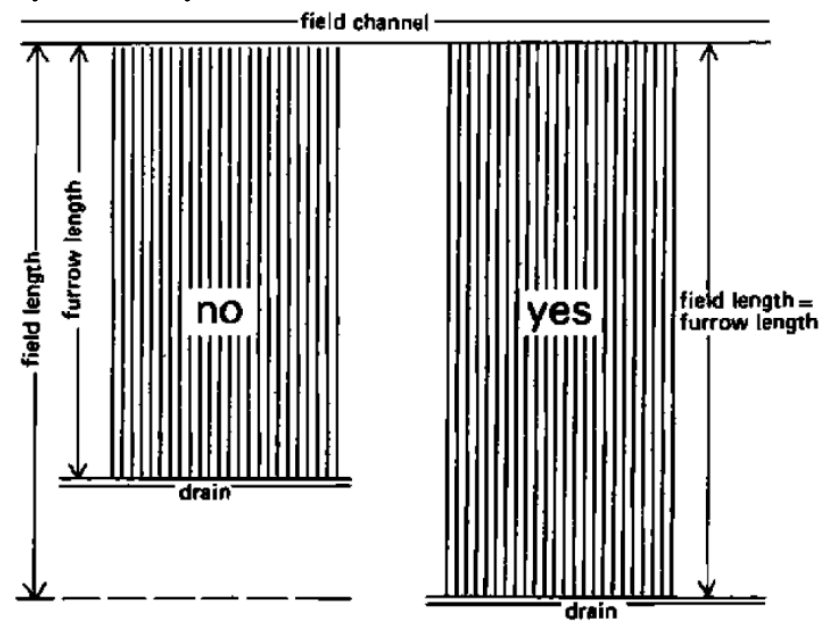

Figure 4. (right) shows ploughed fields.

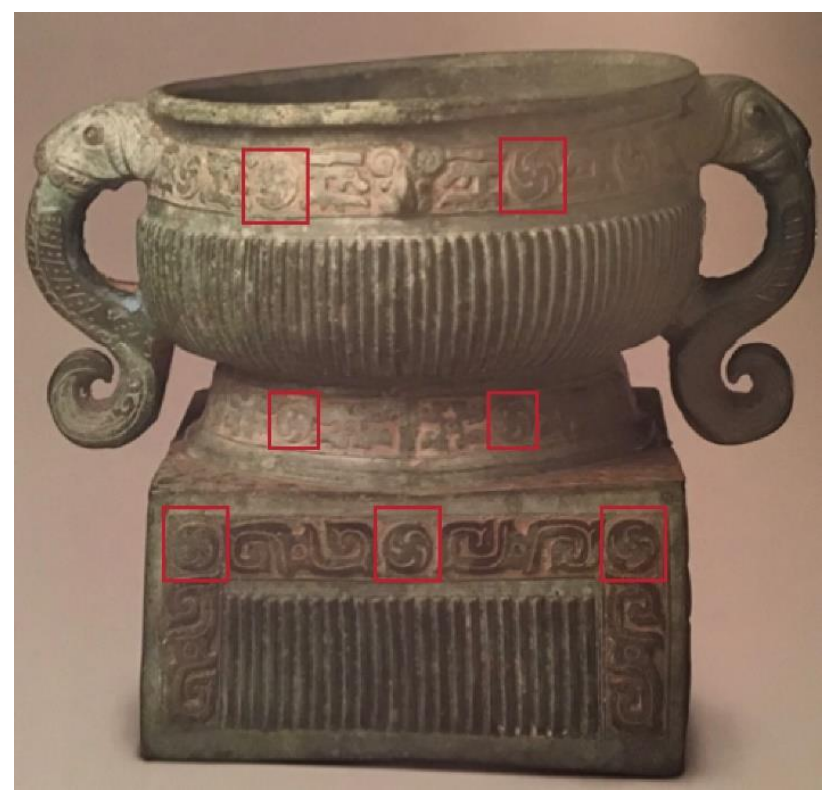

Figure 5. (left) shows the "stream" symbols on Peng Sheng gui.

Historically, many cultures have used trees as landmarks. The inscription here describes two different streams defined by the trees associated with them.

Figure 7 shows the set of symbols used to locate the landmark defining the hamlet named after the pear grove, the "Pear Grove Stream Village" (Feng, 2008).

Therefore, the "pear grove in the valley of Du" is defined in the lower panel of the Peng Sheng gui with alternating symbols for "stream" and "pear tree".

Any local official would be familiar with the landmarks indicated in the inscription. This symbol (Figures 8 and 9), found on the base of the main body, is the symbol for "mulberry", and it alternates with the symbol for "stream". This would thus indicate the hamlet locally referred to as the "Mulberry Tree Village" near the " $X$ " stream as a locative descriptor (Wilkinson, 2018, 230). 


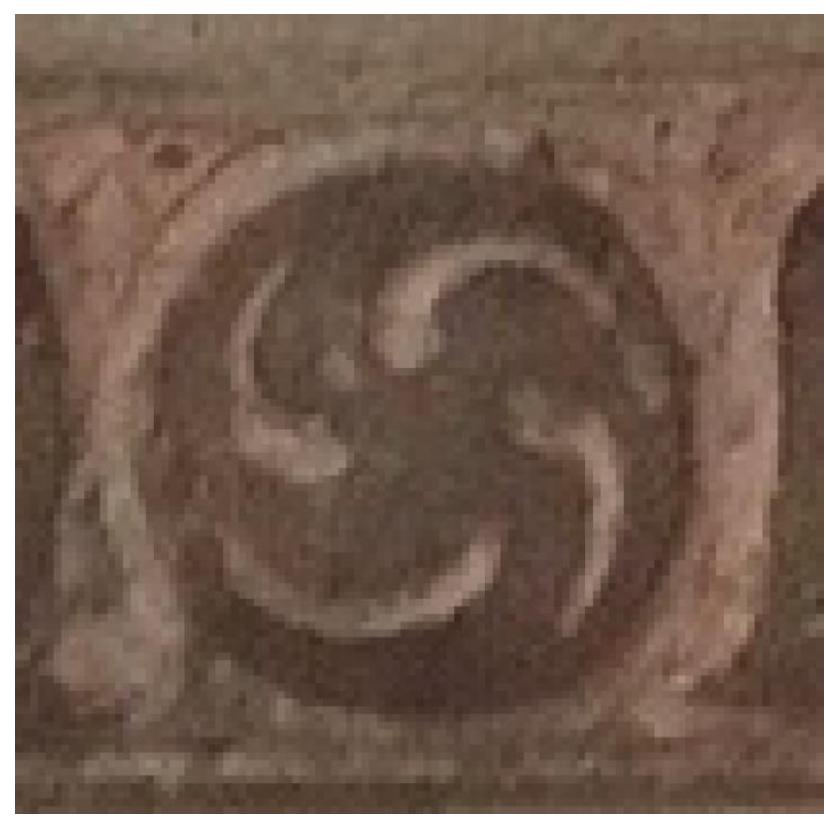

Figure 6. (right) shows the symbol for "stream".
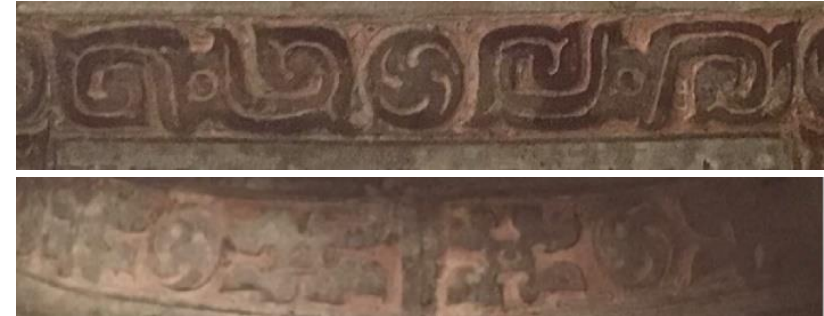

Figure 8. Peng Sheng gui, (left) top section of bottom panel with the "mulberry" symbol.

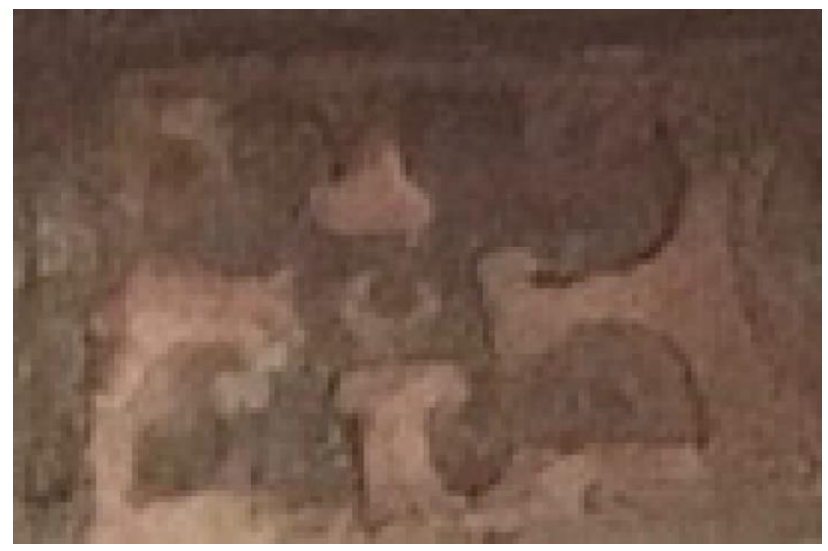

Figure 9. Detail (right) of the "mulberry" symbol.

Thus, it can be concluded that this panel depicts the border of the hamlet bounded by the mulberry grove in the " $\mathrm{X}$ " stream.

The handles of the bronze represent the East Gate (Figure 10), which is described in the inscription as a monument marker-something used in the field by surveyors to demarcate an official, legally standardized locater. Much as the county courthouse cornerstone is used today as the starting point to establish all boundaries within that county, the Eastern Gate would have been a recognized government reference point (Wilkinson, 2018, 231).

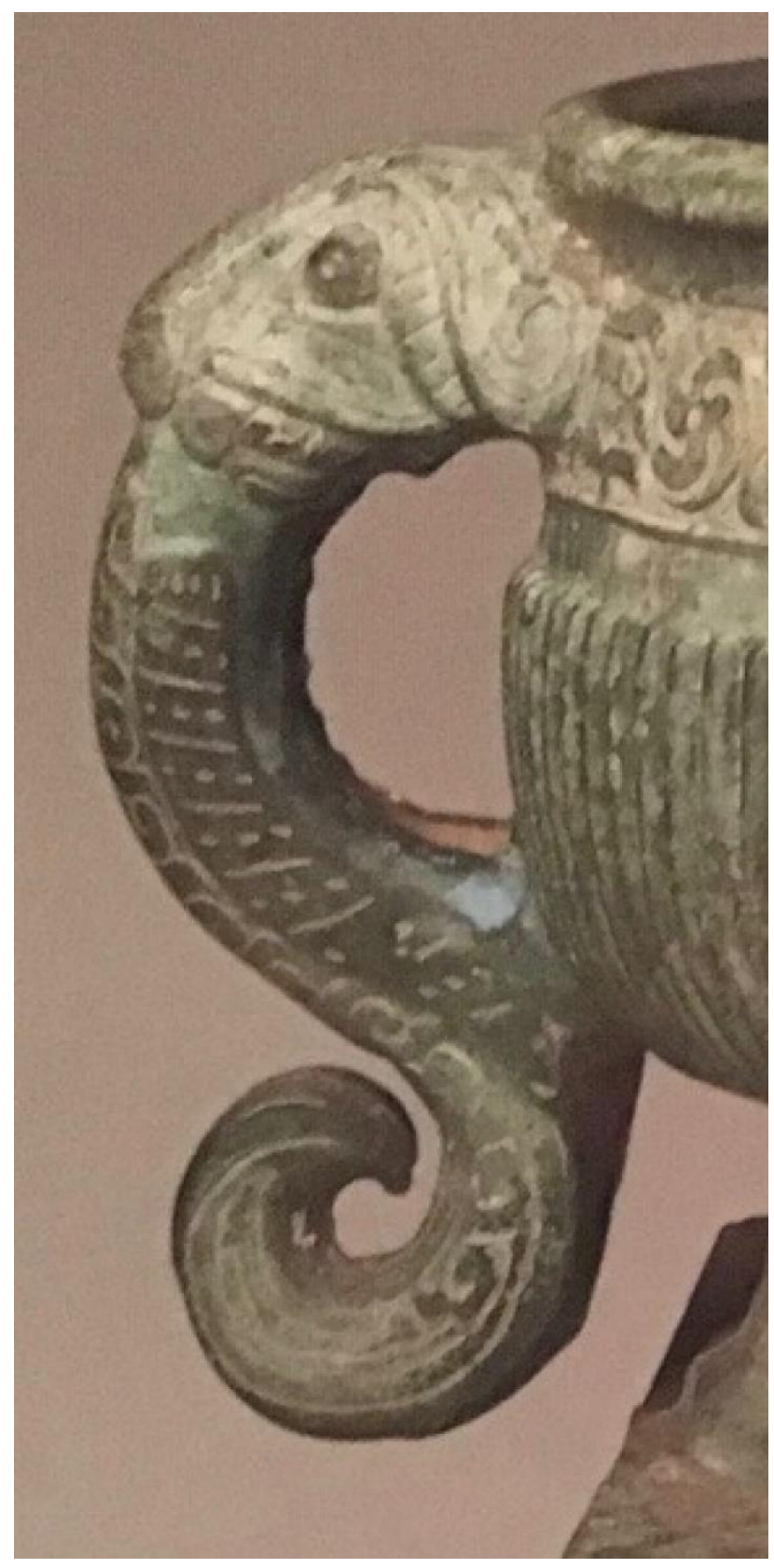

Figure 10. Peng Sheng gui handle.

We can therefore conclude that the handles represented the final point in the survey, the Eastern Gate.

\section{Conclusion}

Many bronze vessels in early China were more than just decorations. They were beautiful, yes, but they were also treasured because they documented land grants. On some vessels, the stylized patterns acted as a survey map. For two thousand five hundred years, no known scholar has correlated the Peng Sheng gui's interior inscription with its exterior decorative symbols.

This paper establishes that the Peng Sheng gui used a standardized set of symbols as a template to document the land. Each of the symbols on the bronze had a meaning that was directly related to the inscription. Any surveyor who had a basic familiarity with the local landmarks and 
the bronze vessel's symbols could reliably and accurately go into the field to verify the locations documented in the inscription. The Peng Sheng gui is only one of many bronze ritual vessels to use surveyor symbols to graphically clarify an inscription involving land.

This discovery is important because the symbols on the Peng Sheng gui can also be found on hundreds of Chinese bronzes across time and space. To date, our research has decoded over fifty cartographic symbols on bronzes, and we are currently able to cartographically interpret dozens of bronzes as land grants from early China (When Ritual Bronzes Ruled China, 2021).

\section{References}

Bronze Ritual Vessels and Musical Instruments from the Complete Collection of Treasures of the Palace Museum. Shou Li Shu Guan Shanghai.

When Ritual Bronzes Ruled China. The San Shi pan Surveyor Plat: Early China's Bronze Rosetta Stone. Surveying and Land Information Science. Accepted 2021.

Eno, R., 2012. Inscriptional Records of the Western Zhou. from https://scholarworks.iu.edu/dspace/bitstream/handle/202 2/23466/3.10-WZhou_Bronzes2010.pdf? sequence $=2 \&$ is Allowed $=y$.

Feng, L., 2008. Bureaucracy and the State in Early China. Cambridge, MA: Cambridge University Press, p. 17.

Feng, L., 2013. Early China: A Social and Cultural History. Cambridge, MA: Cambridge University Press.

When Ritual Bronzes Ruled China the San Shi pan Surveyor Plat: Early China's Bronze Rosetta Stone. Surveying and Land Information Science, 2021

Wieger, S. J. L., 1965. Chinese Characters: Their Origin, Etymology, History, Classification and Signification. New York: Dover Publications, Inc.

Wilkinson, E., 2018. Chinese History: A New Manual. Cambridge and London: Harvard University Press. Onefourth of all Chinese administrative toponyms are hydrological. Plants are common place names, with pine trees, bamboo, plums, and apricots being among the favourites 